\title{
Supply Chain: Next generation issues and concerns
}

\author{
Amit Kumar Sinha* and Prerna Swati
}

School of Design \& Human Engineering, Ulsan National Institute of Science and Technology (UNIST), Ulsan, South Korea

\begin{tabular}{l}
\hline C H R O N I C L E \\
\hline Article history: \\
Received September 10, 2013 \\
Received in revised format \\
10 December 2013 \\
Accepted December 122013 \\
Available online \\
December 142013 \\
\hline Keywords: \\
Supply chain management \\
Bullwhip effect \\
Coordination and collaboration in \\
Supply chain
\end{tabular}

\section{Introduction}

Supply Chain Management (SCM) helps us provide integration of suppliers, factories, warehouses and stores, which facilitate merchandise to produce optimum quantities and distribution to the right locations at the right time (Dan, 2009). The primary objective of SCM is to minimize total system cost while satisfying service requirements. Integration of all areas (purchasing, manufacturing, warehousing and customers) in a firm is a primary requirement of an effective SCM. In the traditional SCM, strategic, tactical and operational decisions are taken separately in a hierarchical form and addressed in sequence. The tactical planning is accomplished by considering various constraints imposed by strategic planning, and operational decisions are decided on the basis of these tactical plans. This approach is more suitable for a firm having the normal management hierarchy, but it

\begin{abstract}
Supply chain is a complicated networking of suppliers, manufacturers, warehouses, distributors information and money. In the modern global manufacturing environment, change has become a constant phenomenon. Change occurs due to fluctuation in technology, environmental requirements, regulatory policies, societal needs and the last but economy is the most important . Uncertainties in supply and demand, globalization of the market, shorter product life cycle, the increasing use of manufacturing product, fast development of information
technology, diversified demand of customer for products distribution and logistics partners are responsible for making more complex supply chain network. Because of all these phenomena emergence of Next-Generation of supply chain management is inevitable. Therefore, in this article we try to incorporate several issues and concerns regarding future supply chain such as natural disasters, problems in outsourcing and import-export issues associated with goods, raw material and several related issues such as taxation, cultural aspects, risk, reliability and last but of supply chain management, the mode of production as well as management is changing from product oriented towards customer's demand or service oriented. Another salient feature of this paper is to demonstrate how to do the planning and management of the next-generation supply chain so that it would maximize profit in the chain rather than maximizing profit of an organization in isolation.
\end{abstract}


constantly creates time lags in decision-making, which facilitates supply chain (SC) inefficiencies. Often, initial assumptions became incorrect due to changes on the ground level and operational decisions become a compromise between what the plan says and what must be accomplished to serve the customers.

The modern supply chain environment is becoming more complex due to the environment of frequently changing optimizations decisions. The ability to respond towards changing of customer's demand is more important as compare to the ability to create an initial optimal plan. In fact, the real problem is not how to plans, but how well one can re-plan. However, it does not mean that strategic or tactical planning is irrelevant. There must be some constant and consistent feedback from operations is necessary; say for example: traditional supply chain planning often operates on a monthly cycle (Cooke, 2000). However, the next generation of supply chain will support a process that is initiated by triggers. There will be a constant monitoring of the environment, measurement of the environment's departure from earlier assumptions and initiation of a strategic planning cycle whenever necessary.

Traditionally supply chains have been characterized by different adversarial relationships between the different contributors of SCM. Due to the limited sharing information with either suppliers or customers, traditional SCM creates a complex difficulty in global environment. Conventionally supply chains have been designed to minimize total system cost while satisfying service requirement of customers. Therefore, many organizations come in the position of risky zone because their response time to the demand changes or supply disruption is too long. IBM released a study on "The Smarter Supply Chain of The Future" It suggested that the future supply chain would be "instrumented, interconnected and intelligent," (Dan, 2009). Today, we are facing more challenge in supply chains because it becomes more complex because of its global orientation. The dynamics of global market have resulted in serious pressure and disruptions to supply chain activities. Supply chain became vulnerable due to uncertain and turbulent environment (e.g. environmental disasters, 9/11, stick actions in Ports). Therefore 'business as usual' is often not an option. Hence, we have to search some new direction in SCM. Ultimately, the purpose of SCM is to integrate all information either from customer's side or supplier's sides and to facilitate manufacturing products for sustaining requirement of global environment or market place. SCM have to create balance between downward cost pressures and the need for its efficiency. The effective supply chain means to response towards fluctuation of customer's demand, quickly. In the next generation of SCM, processes planning, strategic, tactical and operational plans will no longer be viewed as separate entities. They should be viewed in the form of integrated common base interfaces in the next generation of SCM. The supply chain will have a single unified plan, even though at different levels of detail.

The rest of the paper is described in two major sections. Section 2 provides overview of the next generation $\mathrm{SC}$ issues and challenges. In this section we also provide brief information about those areas where Next-Gen of SCM is necessary because of the existing SC, these areas are not competent to face the global problems which are occurring due to globalization or natural calamities. Section 3

describes the necessary steps need to be taken towards next generation (Next-Gen) of supply chain management.

\section{Next-Gen SC Challenges and Issues}

In general, there are six challenges associated with Next-Gen supply chain management (Bauknight, 2000):

(a) Cost effective Green Supply Chain,

(b) New management models dealing with skills, collaboration and outsourcing,

(c) Demand Management and Mass Customization, 
(d) New Technology,

(e) Managing SC uncertainty, complexity, customer responsiveness and risk,

(f) Emerging economies.

For designing next generation of supply chain, we need to spend special attention towards some dimensions, which are covering the above issues. These dimensions are such as configuring the right logistics network, engaging the right alliances and partnerships, developing contingency plans against uncertainties and selecting appropriate production, inventory and distribution strategies (Bauknight, 2000). Increasing level of international trade is usually directly proportional to increase in uncertainty. Thus, we need to identify all these causes, which are responsible for generating uncertainty in the global environment. In addition, we need to develop some strategies to protect against these kinds of disruptions. E-supply chain solutions where Digital economy and Information technologies are incorporated have the potential to contribute in the next generation of SCM with some measurable parameters, such as compressing cycle time, lowering inventories, decision-making quality, reduced overhead costs etc. In the next section, six key concern discussions will be delineated.

\subsection{Supply Chain in Natural Disasters}

Natural disasters are great threats to human beings. They come accidently and usually cause serious damages to millions of people's lives and property. That's why the emergency rescue of natural disasters has been an important task in national emergency management. Emergency supply has been considered as the major obstacle for provide effective rescue due to the limitation of time and poor conditions of transportation.

Natural Disasters and Emergency Management: There are a number of natural disasters, which threats people's lives. Natural disasters are divided into seven types: meteorological disaster, sea disaster, flood disaster, geological disaster, earthquake disaster, agriculture and creature disaster, and forest creature disaster and forest fires. Governmental emergency management is doing a challenging work to prevent the emergency and reduce the side effect of the natural disasters. According to Theodore (1990), it consists of four phases, which is known as P2R2:

(a) Prevention,

(b) Preparation,

(c) Responding,

(d) Recovering.

Fig. 1 describes the mechanism of the emergency management to the natural disaster.

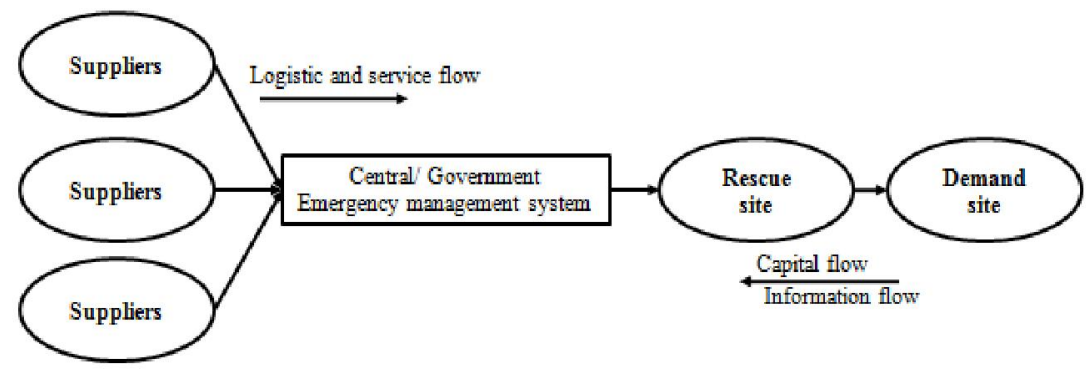

Fig. 1. Emergency supply chain network (Dai et al., 2010)

Emergency Supply Chain Operation Mechanism (ESCOM): The main difference between the emergency supply chain and the ordinary supply chain is that in case of Emergency Supply Chain, the 
core enterprise is replaced by governmental emergency management center. In case of ESCOM, victims of the people belong from the afflicted area, and the providers are mostly those enterprises that have an agreement with the government. The operation of the emergency supply chain is managed by emergency management center (EMC). Emergency Goods Supply Center (EGSC) receives all the emergency goods from the Government Emergency Management Centre (GMEC) and later submits emergency goods to the Temporary Goods Collecting Center (TGCC) (Özdamar et al., 2004). After being sorted and processed at TGCC, the goods are sent out to the afflicted area by distributing center.

Supply Chain System for Rescue of Natural Disaster: Altay and Green III (2006) proposed a model of supply chain system for rescuing people in natural disasters by integrating the emergency management and the SCM model. The model of supply chain system for rescue of natural disaster is technically supported by emergency management information system. The model of Supply Chain System for Rescue of natural Disaster has the following three major sub-systems: (Altay \& Green III, 2006)

(a) Resource stock management system,

(b) Emergency logistic distribution system,

(c) Warning system.

Above suggested information, system facilitates an effective uniformed operation platform for all the systems to operate, to manage, and to integrate all the sub-systems into an entire system. It makes the foundation for emergency management center to make decision and take action.

\subsection{Cultural aspects of Supply Chain Collaborations}

Outsourcing is a mantra for success of manufacturing companies in global environment market. Over the years, China has become the "Factory of the World" (Dan, 2009). In a search of reducing costs, companies have gone to India for services and China for manufacturing. However, during the process of outsourcing many companies forget their inherent cultural issues. At the top level, decision makers are using telephone at the cost of travel to complete their work and its result appears as a form of culture clashes.

Particularly those employees who are living in a large country (geometrically diversify country with homogenous culture like India) became strange when they feel that foreign people are not responding in the same way as they want. The ineffective collaboration of cultural aspects in SCM is responsible for this thing. As a result, some misunderstandings are formed and due to these misunderstandings expected activities are not performed up to the mark.

Finally, for doing work with geometrically diversify people, it is necessary to identify:

- The differences in culture,

- The reaction of people towards any event,

- The key words mean for them (like hello, good morning etc. in different languages),

- The leadership and managerial strategy.

Immigration is responsible for making the global work environment more dynamic. Now in a dynamic work environment people exchange cultural diversity in their day to day work. This helps to resolve some of the problems related with outsourcing. However, to enjoy full advantage of outsourcing, companies need to address the cultural diversity of the future teams. Here we are going to suggest that the process should start with a detailed description of the culture of the country where 
the activity is going to outsourcing. Definitely, it will take some time to explain what is important for people, how they react, what is important for them, etc. Here, we are going to mention one interesting approach suggested by Rae (2009), that once the teams have started working together than we should continue to feed them about the general information of what is happening in the other location. Now general information provided to the working team may include politics, sport, cultural events etc. Such awareness of the system will facilitate discussions among various parties, allowing the members to know each other better, helping in building trust and facilitating communication. In addition, it makes sure that employees should have the knowledge of some words of the other language.

\subsection{Currency fluctuation and Supply Chains}

Today dollar is a primary currency for global trade. That's why we should have a good understanding/knowledge of the fluctuation effect of dollar to the world. Currently dollar is very strong despite of economic uncertainties in the US economy. The smart policy of U.S governments is responsible for making strong dollar. However, right now, in some cases strong dollar is hurting the US industry because it is making American goods much more expensive. As a result, American industries are becoming uncompetitive in abroad.

The factor described in above paragraph is responsible for making decision more complex. Anticipated savings can disappear due to currency fluctuations. Two equally capable suppliers from different companies who had quoted at same US dollar price equivalent have to pay different costs for the buyer over a long contract period. Here we cannot go for forecasting of currency exchange or Hedging of currency. Forecasting of currency changes is an extremely risky task. Companies can go for "Hedging" of currency to offset any high risk associated with fluctuation. However, this policy will again create a problem when dollar becomes weaker because in this situation we will have to pay higher import bill. For making balance decision, we should do different analysis to understand the change in costs under different currency scenarios (Rae, 2009). On the other hand, due to fear of exchange rate changes, companies cannot abandon outsourcing strategies because the fluctuation of exchange rate also provides the opportunity to lower costs. This opportunity can suggest maintaining a maximum level of operational flexibility in terms of sourcing. When contracts are built, buyers also want to eliminate the complexity of problems, which is generating due to fluctuation of currency exchange rate for a given period. This can be accomplished in a form of hedging, as the overseas supplier may authorize a higher unit price for this guarantee (Rae, 2009).

\subsection{Environmental rules and Supply Chains}

Continuous improvement or changing in the rules and regulations of Environmental laws create a challenging task for most of the industries. As a dynamic nature of the electronics industry, environmental regulators have to re-evaluate, or "recast," the basic norms of environmental laws. Due to the above problem in electronic industry, the use of some substance restriction began discussing in global environment during the mid-1990s. As a result, the European Union's Restrictions on Hazardous Substances (RoHS) and its Registration, Evaluation, Authorization and Restriction of Chemicals (REACH) regulations are affecting at each and every level of the electronics manufacturing supply chain (Ferrari, 2008).

The increasing trend in electronic consumer generates high amount of non-biodegradable materials in the environment. These waste caused by the rapid obsolescence of computer and home entertainment products. The Reduction of Hazardous Substances suggest manufacturers to limit the use of hazardous materials (lead, mercury, cadmium, chromium, and some flame retardants) in everything from cell phones and radios to desktop PCs. However, we can easily find some exemption of such types of rule in the servers and networking equipment. Under green manufacturing improvement process these exempted products should be reviewed periodically and eliminated eventually. 


\subsection{Taxation and Supply Chain}

By taking a comprehensive approach towards taxation in SCM, we get significant benefit in terms of overall cost reduction. When company include tax considerations under decision making process then decision makers of the companies are able to make more realistic decisions about where to make, source, locate, move, and store products. On the other hand, users who trade in international market should be incorporated tax information to make a better SCM decision. By considering the tax implications of SC decisions, a company can made a competitive advantage, for example in resourcing or relocating part of the supply chain to a various part of the globe. Therefore, taking the tax information into consideration, decision maker can recommend changes in one's SC structure. All these factors are directly proportional to the company's competitive capability in the global market.

When companies do not include tax information in their supply chain decision-making process then they lose money as well as taken the wrong decisions. For example, a company makes a decision in good faith, believing that it is cost effective to source a product from location A. However, if company were to look for information that included tax details, it would be surprising that the company needs to source the product from Location B and not from location A. What happens at this stage is that the company makes the decision, the supply chain appears on paper to be efficient, but at the end of the period, the company will not make as much money as they expected.

Insular business processes can prevent users from realizing that additional data (i.e. tax-related). It could be improve the quality of their decision-making activities. Ferrari (2008) defined the follwing issues associated with taxation in supply chain:

(a) The costs are higher than they should be (through loss of tax recovery),

(b) Higher rate payment, or penalties and fines for noncompliance,

(c) The company loses competitive advantage,

(d) The business model for implementing the supply chain project in the first place is undermined

\subsection{Risk and Fraud in Supply Chains}

The operational and procurement functions of SC are converging towards fraud. Complex nature in today's global environment is responsible for this fraud. Organizations are facing difficulties of fraudulent activities including theft and product substitution at every step in its SCM. Lastly, the failure to detect and to reduce fraud at the source can be emerged as a form of huge financial losses in the SC and ultimately reached up to the level of consumer injury and death. Detection and way for decreasing changes of frauds in SC needs scrutiny of an organization's activities and these types of scrutiny should be implemented in terms of financial statements. Because of non-detection of fraudulent activities, minor fraudulent activity can turn into a larger one.

Key elements where supply chain fraud happens: Supply chain fraud can cover the maximum area and depth of an organization. It affects activities and relationships inside and outside the organization, involving both occupational and organizational fraud (Guneet). Improper actions of vendors, contractors, and other business partners can also have an adverse impact on company reputation. The results of fraud are invariably more or less the same as that of the results of greater risk, increased losses, decreased profits, in SCM. To minimize losses and mitigate the risk of wrongdoing by business partners, forward-thinking companies take a proactive approach to supply chain risk (Walton \& Princi, 2000). They should:

(a) Conduct due diligence checks on all business partners,

(b) Establish a third-party code of conduct for all business partners,

(c) Assess business partners' culture, controls, policies, and procedures,

(d) Partner with suppliers to remediate control weaknesses and related issues, 
(e) Provide specialized training for key externally facing personnel.

Leading firms protect the integrity of their SC by tracking performance measures such as:

(a) Percentage of potential business partners disqualified during due diligence,

(b) Percentage of business partners in compliance with the company's code of conduct,

(c) Number of business relationships severed for code-of-conduct violations,

(d) Number of supplier control weaknesses and antifraud policy issues cited during audits of business partners.

\section{Steps towards Next-Generation Supply Chain Management}

Here, we are proposing four steps in Next-Generation supply chain management.

\subsection{Evolution in Supply Chain Management}

In the traditional and past supply chains, it was all about operations; hence, instrumentation was the keyword. Recently, with globalization, interconnections arose as the new keyword. According to SC Digest, "Globalization and growing supply chain interdependence have introduced a high level of volatility and vulnerability that is unlikely to subside. Uncertainty has become the norm. This new environment demands a different kind of supply chain which should be much smarter one". Here we are presenting three key factors in evolution in supply chain management, which are Characteristics, Competencies and Smart Risk Management (SRM).

\section{Characteristics and Competencies}

According to Walton and Princi (2000), there are three Characteristics known as $\mathrm{I}^{3}$ which should be incorporated in Next-Gen of SCM
a) Instrumented
b) Interconnected
c) Intelligent

Again, there are following eight factors of Competencies, which should be incorporated in Next-Gen of SCM (Walton \& Princi 2000).
a) Strategy
b) Planning
c) Lifecycle Management
d) Sourcing and Procurement
e) Operations
f) Asset Management
g) Logistics
h) Enterprise Applications

\section{Smart Risk Management}

Apart from Characteristics and Competencies, Smart Risk Management (SRM) is the third most key factors in evolution in SCM. There are following six factors (6I) of SRM, which should be incorporated in the Next-Gen of SCM (Walton \& Princi 2000).

a) Intelligent strategy: risk-based impact analysis

b) Intelligent planning: risk-adjusted inventory optimization 
c) Interconnected sourcing: outsourcing to share risks across the global network and to create variable structures

d) Instrumented operations: visibility for operational risk and control

e) Instrumented asset management: integrated probability-based asset management

f) Interconnected logistics: network integration with variable contingency plans

However, there are four factors from where we have a clear link towards reducing supply chain risk. These four factors are such as (4I)

a) Instrumented enterprise applications: monitoring and real time detection and alerts

b) Intelligent operations: disaster response models

c) Instrumented planning: early warning detection - synchronized demand and supply planning

d) Interconnected strategy: variable cost structures that fluctuate with market demand

\subsection{Innovation in Supply Chain Management}

In a modern way, Innovation is defined as "innovation is a process of turning opportunities into new ideas and putting these into widely used practice" (Tidd \& Trewhella, 1997)

\subsubsection{Lean Concept in Production System}

The lean concept enforces efficiency in all activities in the production and distribution within existing supply chains. In this chain, we work as distributor, producer or supplier at different echelons so as to form value chain in a network like structure.
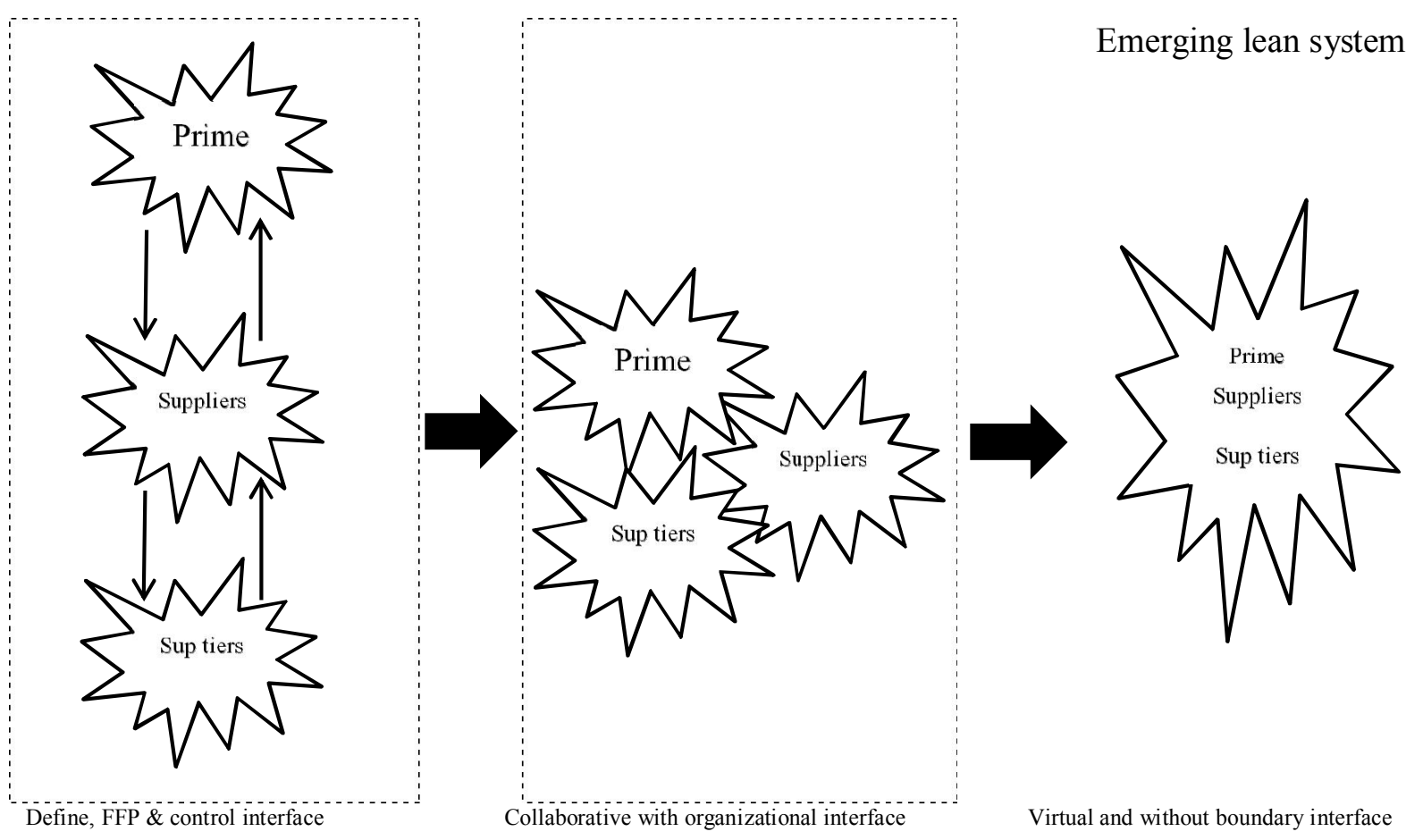

Fig. 2. Trend for early supplier integration into product development (Anderson \& Lilliecreutz, 2003)

Fig. 2 clearly illustrates how the trend is shifting from traditional old approach to emerging approach through competing lean approach. In other words, literature survey as well as practitioners reveals that the next generation of supply chain is the last stage of the development of supply chain, which started from traditional mode and lastly reached up to emerging mode. 
a) Traditional system of supply chain:

$\checkmark$ Clear cut demarcation of field flow interface

$\checkmark$ Rigid interface

b) Learn system of supply chain

$\checkmark$ Collaboration with organizational interface

$\checkmark$ Still somehow rigid interface

c) Emerging lean system of supply chain

$\checkmark$ Virtual interface

$\checkmark$ Without boundary interface

$\checkmark$ vertical three types of mode

Rigid vertical flow field-flow (FFF) interfaces and control is at the prime level of suppliers in the SCM. Such type of transformation demonstrated in Fig. 2 creates strategic relationship between supplier-supplier. Information technology plays a large part for this transition.

\subsubsection{Introduction of Product Development in Supply Chain Management}

Anderson and Lee (2000) proposed four challenges, which occur due to introduction of Product Development in SCM:

(a) Increase freedom of change

(b) Increase the knowledge base and product understanding

(c) Decrease the use of total time and money spent.

The value 'thinking' in a supply chain acts as a major role to compete the global demand of customers. The concept of purchasing and SCM contains numerous perspectives on how to act as a serious buyer and supplier in the supply chain. The interaction between primary suppliers and small and Medium Size Enterprises (SMEs) provides a platform for supply chain innovation. The success of any project is the result of early access of innovative technology and management. Some researchers and practitioners argue that the size difference in between prime supplier and SMEs do not have any correlation among profit sharing and knowledge transformation in new product development (Anderson \& Lilliecreutz 2003). According to our knowledge, it is not always true but it needs more exploration in terms of research and development. Fredriksson et al. (2003) indicated that there was a need for an expansion of the traditional lean concept. "Competitiveness is no longer a result of the effectiveness and efficiency within single corporations only, but rather a result of the cooperation and co-ordination within networks in the industrial value chain".

\subsection{Integration in Supply Chain Management}

It was observed that efficiency of supply chain integration and collaborative initiatives with business partners are two most important factors, which are responsible for providing competitive advantage in SCM. The impact of integrated supply chains can be seen from the following ongoing trends. (It can be easily observed from most explicitly in the high technology and apparel industries.)

(a) Increased globalization of demand and supply given that the volume of all goods and services traded in all industries accounts for $45 \%$ of the world gross domestic product in 1995, as opposed to $25 \%$ in 1970 (Staff 1995).

(b) Ever more demanding customers as buying products anytime, anywhere, cheap and fast becomes the standard expectation of customers in Internet based distribution channels suggested by (Anderson \& Lee, 2000)

(c) Shortening product cycles that demand faster responsiveness of supply chains in addition to decreasing the likelihood of achieving long-term competitive advantage as discussed by (Fine, 1998) 
(d) Proliferation of product variety, which requires the handling of large number of SKUs (SKU stands for stock keeping unit. A company usually assigns a unique SKU number to every different product configuration for track keeping.) and corresponding information.

(e) Time based competition as discussed by Stalk, illustrating the exceptional advantage created from providing products in a more timely and affordable manner than competitors (Stalk, 1988).

(f) Demand Driven Business Models allowing companies to produce only what is demanded - a move from a push to pull systems reflected by initiatives like Just-in-time and efficient consumer response as observed by (Hewitt, 2001).

\subsection{Coordination and collaboration in Supply Chain Management}

By creating new entities and processes within a limited number of strategic business partners of the same SC network could improve their competitive advantage. The required new entities and process is coordination and collaboration of multiple participants in the SCM. For the effective coordination of multiple partners in a SCM, effective and efficient structure in Supply Networks has to be created or manage.

The meaning of coordination is broad, but a good definition in context of the supply chain management is given by Malone and Crowston (1994) as "Coordination is managing dependencies between activities". This inclusive definition of coordination comprises efforts like "Cooperation" and "Collaboration", which have their own connotations of managing dependencies of activities. The definition further suggests that if there is no interdependence there is nothing to coordinate while on the other hand, the higher the dependency the greater the need to coordinate.

Collaboration is defined as "Collaboration means that companies involved are working together to meet one common objective. Collaboration is characterized by the sharing of information, knowledge, risk and profits" by (Mentzer et al., 2000). A more comprehensive definition of collaboration is given by Keskinocak and Tayur (2001) as "Collaboration is closed-loop shared decision making between trading partners that is focused on the end consumer. Collaboration of trading partners on daily decisions, such as the quantity an assortment of orders, delivery dates, product design, and promotions allows aligning the efforts of two or more companies to act like one."

After 1980 when companies began to see the benefits of collaborative relationships than interest in supply chain management with focus on external trading partners has increased steadily (Lummus \& Vokurka 1999).

A six-step collaborative process with each supplier is suggested by Hewitt (2001) as follows:

(a) The supplier generates a statistical forecast and new product introduction information and sends it to the retailer.

(b) The retailer reviews the demand forecast and exceptions. At this point, the retailer can see new product introductions and supply-demand mismatches.

(c) The retailer modifies or updates the forecasts and sends them back to the supplier. Here the retailer indicates, for example, where higher than anticipated demand due to promotions is expected.

(d) The seller sends back the supply-plan information and offers alternatives for exceptions. The supplier has completed the demand/supply matching process and is able to report what it is able to produce and deliver.

(e) The retailer reviews the supply-plan and looks for exceptions. 
(f) The retailer sends back the updated demand information. If there are items that cannot be supplied, the retailer has the option to update the demand information and order substitute products.

\subsubsection{Minimization of Bullwhip effect in Supply Chain Management}

The benefit from coordination through collaboration is best illustrated by common phenomena when no collaboration and information sharing takes place in the SC network. "Time delays in ordering and shipping materials - and failure of decision makers to consider these time delays - cause order variability to increase as one moves upstream in a supply chain". This phenomenon, called the "bullwhip effect". Bullwhip effect is the result of distortion of information from upper level to lower of Decision Makers. It is calculated on the basis of provided industrial data by (Lee et al., 1997). Its manufacturing supply chain simulation models has been proposed by (Sterman, 2000) and the systems dynamics group at MIT. The root causes of the bullwhip effect have been summarized by (Simchi-Levi et al., 1999) as follows:

Demand Forecasting Since there is no visibility of end user data every participant in the chain produces his/her own forecast.

Lead-Time The increase in variability can be seen with higher lead-times. Increased lead times means small changes in the estimate of demand require significant changes in order quantities due to the long time for those replenishment quantities to travel through the replenishment pipeline.

Batch Ordering Batch orders, to exploit economies of scale in transportation and lower ordering costs, create periods with large orders followed by periods of no orders, which introduce further swings in the ordering process.

Price Fluctuation Price discounts lead retailers to stock up on cheap goods, consequently altering the ordering pattern in the following periods.

Inflated Orders When shortage periods are expected to occur, retailers often inflate orders to guarantee enough supply. However, once they are over, retailers go back to old order quantities, which can lead to all kinds of distortion.

\subsubsection{Introducing Dynamic Collaboration in Supply Chain Management}

In the present scenario, coordination in SCN is largely focused between suppliers and manufacturers. Examples of such efforts are vendor managed inventories (VMI), efficient consumer response (ECR), and more recently the use of Collaborative, Planning, Forecasting, and Replenishment (CPFR) models.

\subsubsection{Vendor Managed Inventory}

Vendor Managed inventory (VMI) was developed in the late 1980s. It is the outcome of an effective effort to reduce Inventory and stock-outs at retail stores. Reduction in cost and improvement in service are two benefits of the VMI. In VMI, lower costs are achieved through better demand visibility, reducing the need for large buffer stocks, smoothing of uneven orders, and increase the percentage of low-cost full truckload shipments. Improvement in service from VMI occurs through coordination of replenishment orders and deliveries across multiple customers. Coordination between replenishment orders and deliveries across multiple customers allow inventory balancing across the customer's distribution centers (Waller et al., 1999). 


\subsubsection{Efficient Consumer Response}

Efficient Consumer Response (ECR) started in the early 1993 as a voluntary group in the grocery industry to use technology and strategic alliances to reduce costs.

Frohlich (2002) suggested four key areas of ECR:

(a) Efficient replenishment

(b) Efficient promotion

(c) Efficient introduction, and

(d) Efficient assortment.

\subsubsection{Collaborative, Planning, Forecasting and Replenishment}

In the domain of supply chain management, collaborative planning, forecasting and replenishing are a very famous tool. Collaboratively they are known as CPFR. In 1995, the concept of CPRF was introduced by some industry say for example, Wal-Mart, SAP and Warner Lambert. CPRF concept was introduced with the help of Voluntary Inter industry Commerce Standards Association (VICS). The major objective behind the implementation of CPRF was to provide standardization in process of the product as well as to create common language not only for speaking but also for computer interface (like Java, Matlab etc.)

\subsubsection{Introducing Multi-Tier Collaboration in Supply Chain Management}

The traditional focus on the competitive advantage of single firms is no longer sufficient. Christopher and Towill (2001) argued that due to an increasing number of value and cost conscious customers competitive advantage could not be determined by a firm's individual effort. That's why we go for Multi-Tier Collaboration in SCM. There are following categories among vendors to facilitate multitier coordination in Supply Chain Management.

\subsubsection{Uniform Code Council}

The Uniform Code Council (UCC) is an informal association developed in the early 1970 by the effort of grocery industry to assign uniform product codes (UPC) to manufacturers. The use of UPC codes has allowed to, accurately, identify and track products through supply chains, as well as for retailers and manufacturers to obtain accurate point of sales information. The UCC cannot coordinate by itself. It only sets the communications formats to more effectively track and manage products and inventory in the supply chain. (Abernathy et al., 1999).

\subsubsection{RosettaNet}

RosettaNet is a self-funded, non-profit association of major information technology, electronic components, and semiconductor manufacturing companies, which create and implement industrywide open electronic business process standards. Over 300 companies representing over $\$ 1$ trillion in annual revenues currently participate in RosettaNet's standards development, strategy, and implementation activities. The organization develops Partner Interface Process (PIPs) that define business process between trading partners. Rosetta Net PIPs allow trading partners at all size to connect electronically to process transaction and move information within their extended Supply Chain Management.

\subsubsection{Supply Network Software}

Vast majority of current supply chain applications do not connect supply chain partners. We can eliminate this problem of existing SCM by using 'extended relationship management' (XRM) (Orlov 
et al,. 2000). XRM is the application to connect companies across multiple tiers of the supply network. XRM is collaboration between multiple independent firms to manage supply and demand.

\subsubsection{Electronic Exchanges}

There are numerous forms of electronic exchanges established to facilitate Supply Chain Coordination. Anderson et al. (2000) explained how new business models such as electronic marketplaces - industry vertical marketplaces, private exchanges and horizontal aggregators - can be used as mechanisms to create a synchronized supply chain. Business-to-Business (B2B) and Business-to-Customer (B2C) exchanges are a dyadic collaboration and eventually it facilitates SCM by multi-tier coordination.

\section{Conclusions}

The traditional SC optimization approach contains a systematic implementation of strategic, tactical and operational decisions. However, in the next generation of SC planning processes, strategic, tactical and operational plans will no longer be viewed as separate entities. The supply chain will have a single unified plan, even though at different levels of detail. However, there are several issues and concerns regarding future supply chain such as natural disasters. Natural disasters provide threatening to people's life and from time to time and they disrupt the whole supply chain. Other issues comprises of problems in outsourcing and import-export supply chains such as taxation (related to government or no government organization), cultural aspects (geographical diversity), risk (fraud) and reliability and environmental rules. Several measures have been taken and proposed to overcome above mentioned issues like adoption of lean production systems or implementing collaborative optimizations in supply chain. Another theory proposed for building an efficient supply chain is the information integration theory of supply chains, which accounts ability of a company to with stand sudden disruptions efficiently and effectively.

\section{References}

Abernathy, F.H., Dunlop, J.T., Hammond, J.H. \& Weil, D. (1999). A stitch in time: Lean retailing and the transformation of manufacturing--lessons from the apparel and textile industries: Oxford University Press New York.

Altay, N. \& Green III, W.G. (2006). OR/MS research in disaster operations management. European Journal of Operational Research, 175 (1), 475-493.

Anderson, D.L. \& Lee, H.L. (2000). The internet-enabled supply chain: From the "first click" to the "last mile". Achieving supply chain excellence through technology, 2 (4).

Anderson, H., \& Lilliecreutz, J. (2003, September). The Challenge in Supply Chain Innovation. In 19th Annual IMP Conf.

Bauknight, D. (2000). The future of supply chain - at the heart of the customer-driven enterprise. Company White Paper, Accenture.

Christopher, M. \& Towill, D. (2001). An integrated model for the design of agile supply chains. International Journal of Physical Distribution \& Logistics Management, 31 (4), 235-246.

Cooke, J.A. (2000). The dawn of supply chain communities. Logistics Management and Distribution.

Dai, W., Yan, H. \& Liu, X. (2010). Supply chain system for emergency rescue of natural disastersed. Information Science and Management Engineering (ISME), International Conference of IEEE, 218-221.

Dan, G. (2009). Report on next generation if supply chain management. Supply Chain Digest, May 2013.

Ferrari, B. (2008). Supply chain management challenges in the post financial crisis era, oct. http://www.theferrarigroup.com/supply-chain-matters/2008/10/03/supply-chain-managementchallenges-in-the-post-financial-crisis-era/. 
Fine, C.H. (1998). Clockspeed: Winning industry control in the age of temporary advantage: Basic Books.

Fredriksson, B., Holmberg, G., \& Lilliecreutz, J. (2003). Collaborative Product Development Supported by Modelling and Simulation. SAAB AEROSPACE LINKOEPING (SWEDEN).

Frohlich, M.T. (2002). E-integration in the supply chain: Barriers and performance. Decision Sciences, 33 (4), 537-556.

Hewitt, F. (2001). After supply chains, think demand pipelines. Supply Chain Management Review, 5 (3), 28-38.

Keskinocak, P. \& Tayur, S., 2001. Quantitative analysis for internet-enabled supply chains. Interfaces, 31 (2), 70-89.

Lee, H.L., Padmanabhan, V. \& Whang, S. (1997). The bullwhip effect in supply chains. Sloan Management Review, 38 (3), 93-102.

Lummus, R.R. \& Vokurka, R.J. (1999). Defining supply chain management: A historical perspective and practical guidelines. Industrial Management \& Data Systems, 99 (1), 11-17.

Malone, T.W. \& Crowston, K. (1994). The interdisciplinary study of coordination. ACM Computing Surveys (CSUR), 26 (1), 87-119.

Mentzer, J.T., Foggin, J.H. \& Golicic, S.L. (2000). Collaboration: The enablers, impediments, and benefits. Supply Chain Management Review, 4 (4), 52-58.

Orlov, L., Chatman, B., Schadler, T. \& Howard, E. (2000). XRM: Ebusiness nertwork applications emerge. Forrester Research Brief-11585.

Özdamar, L., Ekinci, E. \& Küçükyazici, B. (2004). Emergency logistics planning in natural disasters. Annals of Operations Research, 129 (1-4), 217-245.

Rae, D., 2009. Recommendation for managing currency fluctuation, 1097-0266.

Simchi-Levi, D., Simchi-Levi, E. \& Kaminsky, P. (1999). Designing and managing the supply chain: Concepts, strategies, and cases: McGraw-Hill United-States.

Staff, W.B. (1995). World development report 1995: Workers in an integrating world: Oxford University Press, Incorporated.

Stalk, G. (1988). Time--the next source of competitive advantage.

Sterman, J. (2000). Business dynamics: Irwin-McGraw-Hill.

Theodore, L. (1990). Accident and emergency management: Wiley Online Library.

Tidd, J. \& Trewhella, M.J. (1997). Organizational and technological antecedents for knowledge acquisition and learning. $R \& D$ Management, 27 (4), 359-375.

Waller, M., Johnson, M.E. \& Davis, T. (1999). Vendor-managed inventory in the retail supply chain. Journal of Business Logistics, 20, 183-204.

Walton, B. \& Princi, M. (2000). From supply chain to collaborative network: Case studies in the food industry, ASCET White Paper, Andersen Consulting 